\title{
La emergencia de la ciudadanía juvenil. Resistencias, paradojas y tensiones en contextos urbanos contemporáneos ${ }^{*}$
}

\author{
Germán Andrés Cortés Millán ${ }^{* *}$
}

Recibido: 5 de marzo de 2015

Evaluado: 27 de mayo de 2015

Aceptado: 1 de septiembre de 2015

\section{Resumen}

El propósito del presente artículo es, más que describir las prácticas y demás expresiones de ciudadanía, comprender las construcciones que sobre estas se han constituido en distintos escenarios juveniles de Bogotá. Este artículo es producto de un proceso de investigación que hizo parte del macroproyecto Construcción de ciudadanías en distintos escenarios sociales liderado por la Universidad Piloto de Colombia en asocio con el Politécnico Grancolombiano, y convocó para este caso tres organizaciones y colectivos de jóvenes pertenecientes a escenarios distintos entre institucionales y no institucionales. Además, se adoptaron acá metodologías cualitativas discursivas, como el grupo focal y las cartografías sociales narrativas, las cuales permitieron acercarse muy claramente a las construcciones categoriales propias del interés del estudio, como las prácticas sociales, la participación y los procesos de empoderamiento y apropiación de los jóvenes en escenarios urbanos.

Palabras clave: ciudadanía, jóvenes, territorio, participación.

\footnotetext{
Artículo de investigación. Derivado del proyecto Construcción de nuevas ciudadanías en diferentes contextos sociales, desarrollada en la Facultad de Ciencias Sociales, de la Universidad Politécnico Grancolombiano. Cómo citar este artículo: Cortés Millán, G.A. (2016). La emergencia de la ciudadanía juvenil. Resistencias, paradojas y tensiones en contextos urbanos contemporáneos. Hallazgos, 13(25), 217-232 (doi: http://dx. doi.org/10.15332/ s1794-3841.2016.0025.10).

** Máster en Planeación Socioeconómica, de la Universidad Santo Tomás (Colombia). Docente Investigador de la Facultad de Ciencias Sociales, del Politécnico Grancolombiano (Colombia). Correo electrónico: gcortesm@poli.edu.co
} 


\title{
The emergence of youth citizenship. Resistors, paradoxes and tensions in contemporary urban contexts
}

\begin{abstract}
The purpose of this article is, rather than describe the practices and other expressions of citizenship, understanding the constructions thereon have become different juvenile stages of the city of Bogotá. The same is the result of a research process that was part of the macro project "construction of citizenship in different social scenarios" led by Pilot Colombia University in partnership with the Polytechnic Grancolombiano, and called for this case three organizations and youth groups belonging different scenarios between institutional and non-institutional. For the same discursive qualitative methods such as focus group and narrative social mapping, which allowed very clearly approaching its own categorical constructions of interest of the study, such as social practices, participation and empowerment processes and appropriation adopted young people in urban settings.
\end{abstract}

Keywords: Citizenship, youth, territory, participation.

Received: March 5, 2015

Evaluated: May 27, 2015

Accepted: September 1, 2015 


\section{A emergência da cidadania juvenil: resistência, paradoxos e tensões nos contextos urbanos contemporâneos}

Recebido: 5 de agosto de 2015 Avaliado: 27 de maio de 2015 Aceito: 1 de setembro de 2015

\section{Resumo}

O propósito do presente artigo é, mais que descrever as práticas e as demais expressões de cidadania, compreender as construções que são constituídas em distintos cenários juvenis de Bogotá. Este artigo é um produto de uma pesquisa que fez parte do macroprojeto Construção de cidadãos em distintos cenários sociais, liderado pela Universidade Piloto da Colômbia em conjunto com o instituto Politécnico Grancolombiano, que convocou para este caso três organizações e grupos de jovens pertencentes a distintos cenários, tanto institucionais como não institucionais. Ademais, se adotaram aqui metodologias qualitativas discursivas, como o grupo focal e as cartografias sociais narrativas, as quais permitiram a aproximação das construções por categorias próprias do interesse do estudo, como as práticas sociais, a participação e os processos de empoderamento e apropriação dos jovens nos cenários urbanos.

Palavras-chave: cidadania, jovens, território, participação. 


\section{LA CIUDADANíA EN PERSPECTIVA}

Hablar de ciudadanía en la actualidad no significa necesariamente abordar un tema innovador o exclusivamente contemporáneo. Todo lo contrario, es la ciudadanía, si se quiere, una da las categorías o concepciones más explicadas, fundamentadas y polemizadas en buena parte de la historia societal. Sin embargo, como lo refiere Honrrach (2009), el concepto se transforma y se hace vigente en consecuencia a los cambios y las demandas contextuales a los que se enfrentan los grupos humanos y sociedades en general.

Vale reportar que son más las versiones que instalan la categoría de ciudadanía con el establecimiento propiamente estatal e incluso con las formas tradicionales de concebir la esfera societal y sus distintas tipologías de desarrollo político. En este sentido, cabe resaltar cómo los ciudadanos encarnan directamente esa escisión e incluso esa paradoja con la política, ya que por un lado se establecen vinculaciones con las formalidades de la democracia y, por otro, aparecen las insatisfacciones propias respecto a un sistema político que no representa los intereses, ni satisface las necesidades de las poblaciones. Esta relación produce tensiones naturales, principalmente para una capa de pobladores ajena al podery desprovista de oportunidades para el ejercicio mismo de la ciudadanía (González, 2007).

Existe una concepción que jurídicamente definió la ciudadanía sobre la base de un contrato social, que incorpora una serie de derechos civiles modernos, como la propiedad, la libertad de expresión, la libre asociación, la libertad de culto, entre otros. De este modo, y según las posturas clásicas, griegas más específicamente, se denominan ciudadanos a aquellos pobladores que gozan de las ventajas proporcionadas por la ciudad en virtud del derecho civil; es decir que el ciudadano se encuentra involucrado e identificado plenamente con los asuntos públicos. Sin embargo, y como consecuencia de los avatares contemporáneos demarcados por la esfera globalizante, el ciudadano resigna parte de su soberanía a cambio de garantías de convivencia social que, con el patrón de acumulación global, los estados nacionales difícilmente se encuentran en condiciones de garantizar.

Es hasta mediados del siglo $\mathrm{xx}$, y con el endurecimiento de la guerra fría que se reproduce la crisis de orden mundial, que además de generar tensiones de carácter estructural para los estados en contienda, crea cambios en la manera de concebir la ciudadanía, pasando de ser descrita de modo unívoco y tradicional a considerarse en dos líneas de comprensión que además de ser antagónicas parecen ser complementarias. Estas son la ciudadanía integrada o global, que define al ciudadano como consumidor, vinculándolo directamente al aparato de producción y de mercado, y la ciudadanía marginal o protociudadanía, en la que se denota una segregación inminente al no pertenecer al aparato productivo, pero que al mismo tiempo posibilita la emergencia de nuevas resistencias y nuevas organizaciones para la reivindicación de derechos principalmente vulnerados por el mercado (Lavolpe, 2008).

Así es como, dentro de la sociedad, la ciudadanía resulta determinada a partir de un marco reglamentario establecido por las instituciones estatales que son constituidas 
socialmente y que tienen como finalidad condicionar los modelos de participación, siendo lo instituyente el cuerpo abiertamente contrario, resistente y en oposición (Castoriadis, 1997).

De acuerdo con esto, cabe referir el dilema respecto a la ciudadanía y su amalgama con el Estado, que parece en muchos casos establecer una relación instrumental en la cual la política se considera una dimensión ajena para las personas. De igual modo, esta formulación concreta de la política pretende no necesariamente la participación de las comunidades en decisiones, ni en determinaciones respecto a su bienestar; por el contrario, se limita a exigir una gestión eficiente del Estado, quien desde su estructura formal y normativa es definida como el único responsable del desarrollo de los asuntos públicos y comunitarios.

Así como la versión instrumental fundamenta todo un paradigma político, de algún modo, tradicional y centralizante, existen otras maneras de concebir el papel de los sujetos en la dimensión política, que pueden catalogarse incluso como emergencias propias de la crisis del Estado. Dentro de esta distinción emergente se pueden situar las denominadas ciudadanías políticas, las cuales se constituyen al margen de la "política institucionalizada", donde incluso se reformula la institucionalidad misma a partir del capital social construido. Entiéndase en este caso capital social como los rasgos propios de la organización social, como son la confianza, las prácticas de reciprocidad y las redes de cooperación cívica; todas estas necesarias para el fortalecimiento, el soporte y el mejoramiento de las comunidades (Putnam, 1996).
Al mismo tiempo, ese movimiento que se reproduce en el interior de las organizaciones y que gesta la emergencia de capital social y nuevas ciudadanías, tiene relación directa con las fortalezas del vínculo social, lo cual indica expresamente que el fortalecimiento de la ciudadanía pasa necesariamente por el fortalecimiento de la vida social, y que el vigor de la acción ciudadana, para restablecer y conducir horizontes de mejoramiento de las comunidades, es al mismo tiempo vitalidad para la sociedad que se transforma. Para esto resulta indispensable considerar el carácter de ciudadanía de manera activa, es decir, estimarle la disposición para la organización en lo público, que parece haber sido doblegada por el sentido privado, propio del mercado y la individualización. Con esto se insiste en lo indispensable de la participación en organizaciones sociales, asunto que además permite adquirir mayor confianza interpersonal, así como mejor percepción de reciprocidad (Lechner, 2000).

Quizás todo esto permite considerar que la categoría ciudadanía se encuentra estrechamente relacionada con la cultura y sus propias transformaciones, para lo cual resulta relevante resaltar el vínculo, hoy indisoluble, entre cultura y política. Con esto se amplía el espectro de lo político al integrar la producción de nuevos significados y nuevas relaciones en proyectos emergentes, y le acuña a la sociedad civil un sinnúmero de virtudes democratizantes dentro de las cuales aparece el reconocimiento de su diversidad interna y su contribución directa en la superación de la visión homogenizadora al Estado.

De lo anterior parece entonces emerger un panorama político y público que integra las nuevas ciudadanías, que parecen trascender 
las tradicionales demandas socioeconómicas, e instalarse en nuevas formas de organización social que pretenden promover la implementación de un proyecto de construcción democrática y de transformación social que integre las dimensiones política y cultural, que incorpore nuevas características en las subjetividades sociales, así como nuevos tipos de derechos, dentro de los que aparecen la diferencia y la equidad (Dagnino, 2005).

Desde estas perspectivas, puede decirse que surgen nuevos sujetos políticos que redefinen los diferentes espacios en los que se encuentran, y de esta manera se logran separar de los parámetros establecidos por la institucionalidad y producir nuevos discursos tanto de denuncia como de propositividad. Es precisamente esta nueva forma de repensar y resignificar las problemáticas sociales y las demandas del territorio que resulta convocante y lo suficientemente atractivo para la población juvenil que de manera activa viene movilizando recursos (Tilly, 1995).

\section{Ciudadanías juveniles en CONTEXTO}

Son muchas las contribuciones y lecturas que hacen referencia a la relación entre ciudadanía y juventud, siendo particularmente las de carácter crítico las que soportan de manera más adecuada y situada las pretensiones propias del estudio. En principio, vale la pena establecer que en ese macroescenario epistémico se resaltan posiciones que exponen lo juvenil desde cierta alternatividad que resulta provocadora y sugestiva. Así pues, lo juvenil, como lo establece Alonso(1999),hace parte de todo un ejercicio deresignificación del sujeto, como sujeto político transformador. Para el caso de los jóvenes, es muy explícita la idea de considerarlo entonces como un sujeto crítico y propositivo en contextos de desarrollo y transformación permanente.

Desde estas perspectivas críticas, que ponen en diálogo directo lo juvenil y la ciudadanía, se puede reconocer además la inclusión del territorio como uno de los componentes transversales para la construcción del joven como sujeto propositivo, ya que en este se disponen nuevas formas de comprensión de las prácticas sociales y se hace del mismo un espacio de reconocimiento (Filardo, 2006). Con esto queda establecido que los jóvenes además de hacer explícitas nuevas prácticas políticas, son portadores tanto de un saber, como de un proyecto de sociedad a la que fundamentalmente perciben como desafiante, excluyente y expresamente desigual (Urresti, 2000). Dicha experiencia propositiva incorpora diálogos y acciones colectivas estéticas que promueven la reivindicación y la participación social y política, en marcos alternativos y plurales.

En esta misma línea teórica, que pone a los jóvenes en dimensión política, aparecen algunos procesos que resultan fundamentales para la comprensión de lo juvenil en perspectiva contemporánea. Estos procesos, que bien se instalan en los actuales movimientos contraculturales o antisistémicos (Wallerstein, 2008), fundamentan muchas de las acciones emprendidas por los jóvenes, las cuales parecen discutir la franja institucional o estructural del Estado y de la sociedad misma, y hacen parte de sus permanentes búsquedas.

Resulta por más indicado, poner un acento, que quizás en los asuntos clásicos sobre 
lo juvenil y sobre la ciudanía no se reporta con la importancia que sí se expresa en las apuestas más alternativas y menos disciplinares. Es el caso concreto de la construcción de lo colectivo y sus múltiples elementos constitutivos, explícitamente reportados en la psicología colectiva y en la sociología política, entre otras, son estos los que parecen darle al análisis de lo juvenil en contexto una aproximación conceptual interesante.

En este sentido y como lo expone Maffesoli (2004), el universo de lo juvenil puede ser explicado a partir de la idea del ser solo desde el ser juntos, es decir que toda acción-en este caso las denominadas como juveniles - se enmarcan en todo un sentido donde lo colectivo privilegia lo individual. Este elemento parece no menor en la perspectiva de las ciudadanías emergentes o nuevas ciudadanías, las cuales insisten en la construcción de nuevos escenarios de visibilidad a partir de nuevas formas relacionales de participación y de organización colectiva, que surgen como respuesta al establecimiento homogenizador del sistema económico, político y social.

Son entonces los procesos de resistencia o disidencia respecto a lo estructural, instrumental y convencional de la política asuntos que abiertamente toman distancia de las perspectivas clásicas y disciplinares que categorizan lo juvenil como sujetos de transición conflictiva (Reguillo, 2008); de esta manera se reconoce no solo el movimiento, sino también los sujetos que lo constituyen, como escenarios propios de la emergencia de lo político y de la reivindicación incluso de los derechos fundamentales.

Así es como el uso del territorio se constituye en una categoría indispensable para repensar lo público y las relaciones de convivencia, precisamente porque es desde el territorio entendido como mapa vital, donde principalmente los jóvenes exponen sus expresiones culturales, sus rituales y sus códigos lingüísticos performativos y simbólicos. Con esto queda explicitado cómo lo juvenil en contexto termina siendo entendido como un escenario de discusión complejo, caracterizado, entre otros, por su exposición multidimensional y holística (Serrano, 2007).

La complejidad que constituye lo juvenil y sus escenarios de desarrollo se afirma con la aparición de intereses organizativos, ideologizados en su mayoría, que antes de desprenderse de lo político, lo reivindican; así, resignifican ideas sobre lo público, lo social y lo territorial, a partir de emergencias simbólicas construidas colectivamente. Es así como para la comprensión de las nuevas ciudadanías, el papel que tienen los jóvenes y sus acciones resulta inmensamente relevante por su pluralismo y por sus explícitas búsquedas de equidad y justicia (Valenzuela, 2007).

\section{TERRITORIALIDADES PARA LA ACCIón}

Vale aclarar que la investigación se sitúa en la ciudad como territorio cultural urbano, constituido, entre otros, por relaciones históricas, discursos institucionales y contrainstitucionales, locaciones, construcciones simbólicas, relatos colectivos, prácticas sociales y formas de participación. La ciudad en este sentido encarna paradojas y contradicciones, especialmente si de lo que se trata es de descifrar su sentido político, ya que en ella se denotan las voces del poder y de la estructura que vigila y controla; también se expresan las necesidades más íntimas de 
la población que reclama, lo cual hace de esta un cuerpo dialéctico que se mueve entre el afán de mantener un establecimiento ordenado claramente alineado y la necesidad de reclamar por los derechos civiles y ciudadanos de sus habitantes e inclusode sus no habitantes (Torres, 2004).

Desde este marco sociopolítico de la ciudad, la ciudadanía aparece como categoría transversal en la concepción y la construcción de territorialidades. Cabe anotar además que la ciudadanía en contexto territorial se constituye hoy en un concepto claramente entensión y expresamente frágil quizás por la aparición y permanencia de fuerzas globalizantes de libre mercado, unidimensionales y hegemónicas, que fisuran la autonomía propia de los estados nacionales y por ende la autonomía de las comunidades en las que se encuentran involucrados los jóvenes, sus identidades y sus prácticas.

Es en este sentido, es definitivo hacer expresa la discusión respecto a cómo el modelo de producción de capitales se constituye al mismo tiempo en definidor y legitimador de distinciones concretas entre lo público y lo privado, circunstancia que parece recrearse también en el espacio y el territorio. Así pues, para efectos del análisis vale considerar cómo el modelo de mercado consolida espacios privados e independientes, que en muy pocos casos posibilitan la participación y la construcción conjunta, asunto que resulta para los jóvenes el pretexto indispensable para ejercer su resignificación y reivindicación como sujetos constructores del territorio.

Esta tensión contemporánea, que va entre la promoción de la ciudadanía y la promoción de formas alternativas para la formación de nuevos sujetos políticos en función de afirmaciones y apropiaciones incluso con el territorio, es precisamente la que constituye un marco de interés para el análisis delas organizaciones, colectivos o estructuras juveniles en contexto, ya que la esta se expresa a partir de la conjugación e imbricación de categorías fundamentales como son la concepción de ciudadanía, las prácticas de ciudadanía y la territorialidad.

Por otro lado y en aras de esclarecer y posibilitar la integración entre asuntos contextuales y propiamente conceptuales relacionados con la ciudadanía, valdría mencionar que así como dicha tensión se expresa y manifiesta de distintas formas, existen otros procesos que permiten reconocer la construcción de nuevas ciudadanías juveniles, como es el caso de la acción colectiva urbana, en la cual se reportan un sinnúmero de expresiones y prácticas múltiples que van desde lo performativo, la intervención del espacio, hasta lo que puramente podría denominarse como apropiación colectiva.

La acción colectiva entonces posibilita para cada uno de los escenarios de organización de los jóvenes la evocación de resistencias y oposiciones, generalmente contra el establecimiento institucional y la estructura de mercado formal, a partir de la construcción deformas relacionales amparadas por la solidaridad y la participación activa, y orientadas al desarrollo de acciones dignificadoras que además responden a la presencia de sentidos e incentivos $\mathrm{u}$ objetivos colectivos, que sin duda soportan la intencionalidad de la acción (Tilly, 1995).Sin ellos, o sin las amenazas que supone encontrarse bajo la subordinación o alineación de una estructura de poder, bien podría considerarse la acción colectiva como innecesaria y descontextualizada. 


\section{Metodología}

El proyecto de investigación se construye en el marco de la investigación cualitativa, por su naturaleza, forma de organización y análisis de la información, con énfasis descriptivo e interpretativo, precisamente por su intencionalidad de comprender los discursos juveniles que sobre ciudadanía se reportan en escenario urbanos contemporáneos. La estrategia metodológica incluyó técnicas gráfico-conversacionales como las cartografías sociales y técnicas narrativas, como los grupos focales de discusión.

La ruta metodológica asumida para el proyecto posibilitó la integración de la información a partir de matrices de sentido, en las que cruzaron las categorías con fragmentos textualizados y con su correspondiente análisis. En este sentido y haciendo claridad respecto a la posición epistemológica que soporta la investigación, cabe mencionar que es por medio del análisis de discurso que se lograron acentuar las expresiones narrativas evocadas con las distintas estrategias metodológicas dispuestas.

\section{Procedimiento}

Fase I: revisión documental. Levantamiento del estado del conocimiento.

Fase II: selección de las organizaciones juveniles.

Fase III: acercamiento a las organizaciones juveniles y socialización del tema central de la investigación.

Fase IV: desarrollo de estrategias metodológicas. Teniendo en cuenta el carácter descriptivo e interpretativo de la investigación, se dio lugar en primera instancia al grupo focal con cada uno de los grupos seleccionados. En una sesión posterior se realizó la cartografía social con los grupos seleccionados.

Fase V: organización y análisis de la información. Para la organización de la información recogida a través de los métodos de investigación, se realizó la transcripción del grupo focal de discusión y las propias de las cartografías sociales. Posteriormente se dispuso el análisis en matrices de doble vía.

Fase VI: discusión final, conclusiones y sugerencias del ejercicio.

\section{Participantes}

El proyecto de investigación incluyó18 jóvenes representantes de tres escenarios juveniles distintos (contexto universitario, colectivo no institucional y grupo juvenil institucionalizado perteneciente a programas de la Secretaría de Integración Social).

Por otro lado, resulta indispensable clarificar las categorías de análisis con las que se dio lugar a la demarcación misma del ejercicio. Estas fueron: concepción de ciudadanía, prácticas de ciudadanía, relaciones con la institucionalidad y participación social.

\section{Análisis de resultados}

A continuación se presentan los resultados de la investigación, organizados por categoría y soportados a partir de fragmentos textuales evocados en las estrategias metodológicas utilizadas.

\section{CONCEPTO de CIUdAdanía}

Respecto al concepto de ciudadanía, puede decirse en principio que, si bien son 
distintas las posiciones de los jóvenes de acuerdo con su relación con el territorio y la institucionalidad, parecen evidenciarse posiciones abiertamente clásicas en muchos casos. Para algunos jóvenes la ciudadanía se constituye a partir de la conjugación expresa de los deberes y derechos, con los cuales se orientan marcos relacionales de respeto y reconocimiento a la diferencia. Como lo plantea Durston (1999), existe un modelo de ciudadanía que pretende mantener cierto equilibrio desde la incorporación de normatividades que guían la relación entre el individuo y la sociedad, lo cual le otorga la posibilidad de participar activamente: “Es una posición dentro de la sociedad que comparten diferentes personas que se acogen a una serie de normas y leyes que los relaciona entre sí". "La ciudadanía es algo que formaliza a una persona dentro de un sistema regido por normas". "Son un conjunto de deberes, derechos con los que cuenta la población, la cual se interesa en todo lo que sucede a su alrededor" (comunicación personal).

A partir de lo anterior se puede establecer cómo los jóvenes relacionan de manera directa la ciudadanía con formas estructurales diseñadas y formalizadas por el Estado, muy en función de reconocer el marco reglamentario que parecen soportar las relaciones cotidianas. Esta perspectiva formaliza a los jóvenes como miembros de una colectividad que contiene y preserva objetivos comunes relacionados con la convivencia pacífica y con el bienestar individual y social (Calle, 2007).

Así mismo, en este aspecto categorial aparecen algunas apuestas que bien pueden considerarse como alternativas o emergentes, ya que hacen referencia a la expresión activa, a la participación y a la opinión crítica que los mismos jóvenes denominan como parte indispensable de la ciudadanía. Esto queda expresado en afirmaciones como los siguientes:

Además es importante que nos reconozcamos como sujetos del cambio y la transformación, lo cual significa establecer nuevas formas de relación como la solidaridad y el trabajo desde la confianza". "Expresarnos de forma artística, así otras personas no lo vean de esa manera". "Podemos construir entre todos decir somos parte de esta sociedad de una ciudadanía y podemos respetar usted allá y respetar cada pensamiento rompiendo imaginarios". (Comunicación personal)

Con lo anterior puede verse cómo para los jóvenes que exponen prácticas culturales, $\mathrm{u}$ otras de carácter asociativo u organizativo, su ejercicio permite tanto la interlocución permanente con estructuras formales, como con la ciudadanía cotidiana que reconocen en su ejercicio, apuestas no formales e incluso de resistencia que promulgan o promueven maneras distintas de construir nuevas relaciones a partir de valores como el respeto, la responsabilidad y la solidaridad, entre otros, que los llevan a convertirse de manera simbólica en sujetos empoderados en espacios de participación (Ortiz y Vargas, 2011).

\section{Prácticas de ciudadanía}

Otra de las categorías que hacen parte del cuerpo de sentido del proyecto hace referencia a las prácticas de ciudanía que se 
desarrollan por parte delos jóvenes en diversos espacios de la ciudad. Es importante en este sentido aclarar que por práctica de ciudadanía se entiende toda acción pública o privada que es constituida por una carga identitaria, ideológica o cultural, sugerida a parir de un interés colectivo, y que se manifiesta plural y diferencialmente de acuerdo con las condiciones del contexto de las comunidades. Desde la perspectiva propia de las ciudadanías emergentes, resulta relevante clarificar que ese interés colectivo pasa por la construcción misma de escenarios de convivencia, de la cual hacen parte múltiples prácticas que afirman, desde la utilización del espacio, derechos fundamentales.

Teniendo en cuenta lo anterior, las narraciones y expresiones de los jóvenes permiten reconocer y dar cuenta de la importancia de las prácticas en la comprensión de la ciudadanía, como puede hacerse evidente en los siguientes fragmentos: "El grafiti es el periódico o el noticiero que no le da miedo decir la verdad directo completo". "El grafiti lo que hace es fortalecer la comunicación". "Tomarse una calle la comunidad para conocerse, hacer actividades que fortalezcan el vínculo, es indispensable para cambiar las cosas". "En la calle se reconocen los problemas, y casi siempre nos involucra. Por lo tanto hay que solidarizarse y actuar todos juntos, desde para arreglar el parque, hasta denunciar todos ante las autoridades". "Los proyectos los construimos en parte por el apoyo de la Secretaría, que ha entendido que debemos visibilizarnos a partir de la cultura. Es un diálogo constante que es importante para que hoy hagamos lo que hacemos".

Puede decirse entonces que existe una mirada muy particular de la práctica de ciudadanía que involucra directamente el espacio público, el cual representa el escenario de articulación de las expresiones con los distintos interlocutores. Además de esto, resulta interesante ver cómo los matices diferenciales expresados en la tipología de organización juvenil permiten situar la práctica con el espacio, también de forma distintiva.

En este sentido, las prácticas pueden verse como apuestas propiamente alternativas y resistentes al establecimiento, como también acciones alineadas a marcos institucionales que representan unos ciertos valores propios hacia lo juvenil. Así pues, el espacio no solo se convierte en escenario para la exposición e interlocución con lo público, sino que además posibilita la construcción de sujetos para la acción, es decir, sujetos políticos

\section{RELACIONES CON LA INSTITUCIONALIDAD}

Esta categoría resulta fundamental en la comprensión de las ciudadanías y nuevas ciudadanías construidas por los jóvenes en contextos urbanos. Sin embargo, cabe anotar que las categorías anteriormente expuestas dan sentido constitutivo a las relaciones con la institucionalidad, precisamente porque es a partir de estas relaciones que emergen y constituyen los discursos juveniles y sus correspondientes prácticas.

Es indispensable para el análisis mencionar que las relaciones con la institucionalidad están enmarcadas principalmente por aquellas que hacen alusión al establecimiento, a sus marcos normativos, a las formalizaciones de control y cohesión y demás asuntos propios del Estado. En este aspecto, pareciera que las instituciones y sus convenciones 
y establecimientos instauran parámetros para controlar a los distintos actores sociales, asunto que podría beneficiar sectores y excluir otros, entre los que se encuentran los jóvenes (Durston, 1999).

Si bien los discursos anteriores de los jóvenes parecen llevar implícita esa relación con las instituciones, los siguientes parecen hacer expresarla de manera directa: “Grupos juveniles como las tribus urbanas actúan de formas diferentes y cada una propone un modelo de ciudadanía distinto al de otros grupos, ya que se basan en sus ideales y no necesitan del Estado para existir". "Somos ajenos a cualquier planteamiento que nos amarre, el Estado quiere siempre controlar, pero hemos podido hacer muchas cosas sin tener que recurrir a nadie, lo que se llama pura autogestión". "Hay que ser muy estratégicos con relación al Estado, no quiere decir que no sea importante. Lo que creo es que muchas veces se aprovecha la actividad nuestra, en otros casos aparecen espacios para construir cosas" "De la mano de la Alcaldía y de la Secretaría especialmente, son más visibles nuestras acciones".

Según estos fragmentos puede decirse que los marcos relacionales construidos entre los jóvenes participantes y la institucionalidad tienen también matices distintos. Por un lado, aparecen las posiciones no alineadas $\mathrm{o}$, si se quiere, contestatarias o resistentes a la estructura, centro de poder o institucionalidad, en las que se explicita una relación conflictiva y difusa que desconoce toda base orientadora desarrollada por parte del Estado y sus instituciones constitutivas. En este sentido, la mirada contrainstitucional posibilita en los jóvenes iniciativas autogestionadas que resultan no solo sugestivas, a la hora de convocar interlocutores, sino también contestatarias, críticas y al mismo tiempo propositivas.

Por otro lado, se explicita otra tipología de relación con el Estado que parece considerarse como estratégica y mediadora, al denominarlo y comprenderlo como agente promotor de iniciativas juveniles en la ciudad. Se considera como posición estratégica debido a que se sirve de los agenciamientos del Estado para visibilizar lo juvenil en escenarios plurales.

A partir de lo anterior, puede decirse que la relación con la institucionalidad está mediada por elementos distintos, que pasan desde la comprensión de la normatividad y la estructura formalizada por la institucionalidad, que marca horizontes respecto a lo juvenil, hasta la clara demarcación de fronteras y distancias con el Estado y con sus instituciones, principalmente por considerarlo restringido y, si se quiere, limitante respecto a las dinámicas e iniciativas propias de los jóvenes, así como también por considerarlo como el establecimiento objeto de sus resistencias y denuncias.

\section{Participación social}

Como última categoría de análisis del estudio, considerada además como fundamental en la comprensión de las nuevas ciudadanías juveniles urbanas, aparece la participación social. Con esta categoría, y con su integración a las reflexiones sobre las anteriores, finalmente se termina de configurar el escenario para el análisis crítico, el cual fundamenta el sentido del ejercicio.

Es importante establecer que siendo la participación social una dimensión abiertamente 
compleja y llena de elementos constitutivos, en el siguiente análisis se abordarán algunos considerados como transversales. En este sentido, y como lo propone Valenzuela (2007), la participación conjuga un marco plural de estrategias que permiten la adecuada integración del joven al mundo político, que puede contemplar su presencia en espacios formalizados, en la construcción de iniciativas para la convivencia colectiva y en la apropiación misma de lo público y sus dispositivos.

Estas consideraciones respecto a la participación social y a sus múltiples formas de expresión que le dan sentido pueden reconocerse explícitamente en los siguientes fragmentos: "La ciudadanía se trata como de revolucionar lo ya establecido, y para ello hay que actuar organizada y colectivamente". "Comenzamos a trabajar recuperando espacios y hacerlos propios. Es indispensable que la gente pueda cuestionarse respecto a lo que hacemos, ya que es un trabajo serio y constante". "Si se están creando nuevos ciudadanos, en este mismo momento estamos haciendo un nuevo tipo de ciudadanía al debatir y al crear. Los colectivos tienen planes y los ponen en marcha. A veces las instituciones limitan, pero siempre hay formas para decir lo que se piensa". "El concepto cambia a partir de los nuevos eventos socioculturales que generan crítica. Las redes sociales (integran) logrando que se obtenga una participación más abierta en diferentes temas, en especial en el contexto político". "Son estas redes nuevos escenarios para participar activamente".

Con los anteriores fragmentos se puede dar cuenta de las distintas maneras de vincular la participación juvenil en el escenario urbano contemporáneo. Por un lado, se manifiesta de forma directa cómo la participación supera o trasciende las estrategias formales; por otro lado, se hacen evidentes intencionalidades y propósitos concretos respecto a las formas como que actualmente los jóvenes se movilizan y actúan.

En este sentido práctico, se hace explícita la idea de la participación juvenil dentro de un marco organizativo con expresiones cada vez más colectivas, que pretenden desplazarse de las rígidas definiciones estructurales y que a su vez contemplan el desarrollo y la consolidación de un sentido político alternativo que los vincula con el escenario de debate público.

Otro de los elementos fuertes en este aspecto de la participación social tiene que ver con la comprensión de otros territorios para el diálogo, la interlocución, la denuncia y la propositividad. Dichos territorios incluyen estratégicamente nuevas prácticas y nuevas relaciones, y van desde la utilización del espacio público y su intervención colectiva, hasta las apuestas que involucran las nuevas tecnologías; no desde la utilización instrumental de lo digital, sino desde la concepción estratégica de las plataformas informativas en función de la promoción de ideas y proyectos.

Por último, vale resaltar la manera como estas iniciativas que surgen desde lo juvenil y que parecen en principio definir sus nuevas formas de integración al escenario político y de construcción de lo público trascienden a los jóvenes en sí mismos y vinculan otros actores como activos y determinantes en los procesos de participación social, como son las generaciones distintas, las instituciones, los medios de comunicación y hasta el Estado. 


\section{Conclusiones}

Tomando como base lo anteriormente mencionado, es claro que las conclusiones del proceso se instalan en un espectro amplio y plural, pero al mismo tiempo interdependiente y complejo, al involucrar no solo las categorías inscritas para el ejercicio, sino también otros componentes de contexto que posibilitan una mejor comprensión del proceso. De esta manera, las conclusiones que a continuación se expondrán se enmarcarán en lo categorial, en lo procesual yen lo contextual, respectivamente.

Con relación a lo categorial puede decirse que aparecen diferencias propias de las tipologías de los grupos que se hacen manifiestas respecto a la forma de concebir la ciudadanía; también hay algunas aproximaciones explícitas que resultan interesantes, como puede ser considerar la ciudadanía como un tema cercano y de incidencia directa para con las prácticas desarrolladas por los mismos.

Si bien el carácter institucional no desaparece, sí se resignifica la manera como este media en la construcción de ciudadanía juvenil. En este sentido, parece que la construcción de ciudadanía trasciende la relación directa con lo institucional, y si se quiere con el Estado, y se afianza en la conformación de nuevas prácticas e interlocuciones con el territorio y con sus actores, a través de la implementación y el desarrollo de formas y estrategias estéticas, discursivas y no necesariamente convencionales o formalizadas.

Así es como el territorio cobra un sentido particular, no solamente porque permite resignificar la esfera de lo público, sino también porque posibilita el establecer distintas formas de interlocución con lo institucional y lo abiertamente instrumental, estructural y normativo. En este sentido, se concluye que los distintos grupos juveniles participantes del proceso contemplan la idea del territorio como escenario plural, donde convergen iniciativas y discursos formales; un escenario del cual que para los jóvenes resulta indispensable hacer parte, pero discutiéndolo al mismo tiempo.

Por otro lado y no menos importante, resulta la comprensión de la ciudadanía como concepto. Este aspecto que aparece transversal involucra tipologías de reconocimiento abiertamente distantes, muy en función del tipo de relación que se construye con la institucionalidad o con la estructura. Es decir que, en la medida en que los jóvenes se sientan representados e incorporados en los discursos instituidos, su concepto de ciudadanía circula más e la perspectiva formal o tradicional de relación entre derechos y deberes. Si, por el contrario, los jóvenes toman distancia respecto a la estructura institucional, por no sentirse representados, estos consideran la ciudadanía a partir de nuevos marcos relacionales soportados principalmente por sentidos colectivos, participación democrática, oportunidades para la acción y procesos autogestionados.

Otro de los elementos para resaltar del proceso tiene que ver con lo público y sus consideraciones epistemológicas y prácticas, para lo cual vale referirlo como trasversal en las apuestas sobre las nuevas ciudadanías. Es en este sentido, lo público trasciende la idea formal del espacio y el territorio, y se instala en la construcción colectiva de agendas propias para la denuncia, la movilidad y la expresión identitaria, que promueve la 
participación activa en procesos vinculantes de gestión tanto institucionales, como no institucionales.

Por esta razón, el espacio y el territorio urbano resultan más que estratégicos para la puesta en escena de las distintas formas de visibilización de lo juvenil y sus discursividades, que incorporan desde prácticas vinculantes, democratizantes e incluyentes, hasta agendas alternativas y propositivas para la interlocución con el Estado, con la institucionalidad y con la sociedad civil en general, en las que se evoca explícitamente un joven reflexivo y transformador.

Para finalizar, es importante clarificar que el tránsito de la ciudadanía tradicional o clásica, a las nuevas ciudadanías, tiene diversos y complejos elementos constitutivos, como son el contexto sociopolítico donde se construyen los discursos y se operacionalizan las prácticas, los significados culturales que denominan y enuncian lo juvenil como etapa o fase del desarrollo, que distan explícitamente de su consideración política, y los esfuerzos colectivos que emergen de grupos y organizaciones juveniles, provenientes de universidades, barrios e incluso de las instituciones públicas.

Son entonces los jóvenes actores protagonistas directos en la esfera de lo público, y por lo tanto activos en sus formas de debatir y denunciar, así como en las propiamente relacionadas con la construcción de sociedad. Con esto lo que explícitamente manifiesta la investigación es la posibilidad que sobre lo político tienen los jóvenes de resignificar su papel en los asuntos propios de la ciudad y de cada uno de sus entornos decisorios en los que participan junto con otros actores sociales.
Con esto lo que puede concluirse es que si bien la tipología es diversa, ya sea por su denominación, afiliación, naturaleza o prácticas, de los grupos juveniles en la ciudad, existe una necesidad de dichos grupos por instalar en espacios convencionales o no convencionales su apuesta por una ciudadanía activa, itinerante, alternativa y claramente sujeta a valores que privilegian la creatividad, la colaboración y la colectividad como grandes insumos para la transformación del espacio, de lo público, de las instituciones y de la misma ciudad, que de manera paradójica los acoge pero que al mismo tiempo los excluye y los invisibiliza.

\section{ReFERENCIAS}

Alonso, L. (1999). La juventud en el tercer sector: redefinición del bienestar, redefinición de la ciudadanía. Estudios de Juventud, (45), 9-20.

Calle, M. (2007). Formación en valores: una alternativa para construir ciudadanía. Tabula Rasa, (6), 339-356.

Castoriadis, C. (1997). El imaginario social instituyente. Zona Erógena, (35), 1-19

Dagnino, E (2005). Meanings of citizenship in Latin America. Brighton: Institute of Development Studie.

Durston, J. (1999). Limitantes de ciudadanía entre la juventud latinoamericana. Última Década, 1-4.

Filardo, V. (2006). Uso de los espacios urbanos. Análisis de cinco grupos de discusión. Documento de Trabajo № 75. Facultad de Ciencias Sociales, Universidad de la República.\}, Uruguay.

González, J. (2007). Ciudadanía y cultura. Bogotá: Universidad Nacional de Colombia, Centro de Estudios CES. 
Honrrach, J. (2009). Sobre el concepto de ciudadanía: historias modelos. Factotum, (6), 1-22.

Lavolpe, F. (2008). Las nuevas ciudadanías de la globalización. Hologramática, 47-65.

Maffesoli, M. (2004). Debates sobre el sujeto, perspectivas contemporáneas. Bogotá:Siglo del Hombre.

Putnam, R. D. (1996). Alone America's declining social capital. Journal of Democra$c y, 6(1), 65-78$.

Lechner, N. (2000). Nuevas ciudadanías. Revista de Estudios Sociales, (5), 1-8.

Ortiz, M. y Vargas, Y. (2011). Escenarios culturales de los jóvenes y participación ciudadana. Culturales, 7, 125-158.

Reguillo, R. (2008). Instituciones desafiadas. Subjetividades juveniles: territorios en reconfiguración. Revista de Teología, Ciencias Humanas y Pastoral, (1), 211-230.

Serrano, J. (2007). Filosofía actual en perspectiva latinoamericana. Bogotá: Universidad Pedagógica Nacional.
Tilly, C. (1995). Los movimientos sociales como agrupaciones históricamente específicas de actuaciones políticas. Sociológica, (28), 1-18.

Torres, A. (2004). Identidad y política de la acción colectiva, organizaciones populares y luchas urbanas en Bogotá.Bogotá: Universidad Pedagógica Nacional.

Urresti, M. (2000). La relación entre los cambios culturales de fines de siglo y la participación social y política de los jóvenes.En S. Balardini (Ed.). La participación social y política de los jóvenes en el horizontedel nuevo siglo (pp. 177-206). Buenos Aires: Consejo Latinoamericano de Ciencias Sociales [Clacso].

Wallerstein, I. (2008). Historia y dilemasde los movimientos antisistémicos.Bogotá: Desde Abajo.

Valenzuela, K. (2007). Colectivos juveniles: ¿inmadurez política o afirmación de otras políticas posibles? Última década, (26), 31-52. 